\title{
Unmatched Type 0 RhD+ Red Blood Cells in Multiple Injured Patients
}

\author{
Sabine Flommersfeld ${ }^{a}$ Carsten Mand ${ }^{b}$ Christian A. Kühne ${ }^{c}$ Gregor Bein $^{d}$ \\ Steffen Ruchholtz ${ }^{\mathrm{b}}$ Ulrich J. Sachs ${ }^{\mathrm{a}, \mathrm{d}}$ \\ ${ }^{a}$ Center for Transfusion Medicine and Hemotherapy, University Hospital Gießen and Marburg, Marburg Campus, Marburg, Germany; \\ ${ }^{b}$ Department of Trauma, Hand and Reconstructive Surgery, University Hospital Gießen and Marburg, Campus Marburg, Marburg, Germany; \\ ${ }^{\mathrm{c}}$ Asklepios Klinik Wandsbek, Hamburg, Germany; \\ dInstitute for Clinical Immunology and Transfusion Medicine, Justus Liebig University, Gießen, Germany
}

\section{Keywords}

Non-cross-matched transfusions - Type O RhD+ supply · Emergency transfusion - Alloimmunization

\section{Summary}

Background: Immediate supply of red blood cell (RBC) concentrates is crucial in the initial treatment of exsanguinating patients in the emergency room. General shortage of RhD- RBCs has led to protocols in which patients with unknown blood groups are initially transfused with group $\mathrm{O}, \mathrm{RhD}+\mathrm{RBC}$. Limited data are available regarding the safety of such an approach. Methods: Transfusion protocols for all multiple injured patients from the regional polytrauma database were retrospectively analyzed over a period of 5 years. Data on side effects were retrieved from the local safety update registry. Follow-up data were obtained from patients with identified RhD-incompatible transfusions. Results: In total, 823 patients were registered as multiple injured in the database. An immediate transfusion of 259 units (mean number of units 4, range 1-6) group $\mathrm{O}, \mathrm{RhD}+\mathrm{RBC}$ s was initiated in 62 of them. 14 of these patients were RhD- and received 60 units of RhD-incompatible RBCs in the emergency room. In the later course RhD- patients received additional 185 incompatible transfusions (13; 1-31). The overall seroconversion rate was $50 \%$. No adverse outcome due to incompatible transfusion was observed. Conclusions: Initial supply with group O, RhD+ RBCs in multiple injured patients appears to be safe. Significant numbers of RhD- units can be saved for use in other patients.

(c) 2018 S. Karger GmbH, Freiburg

\section{Introduction}

Immediate supply with red blood cells (RBCs) is a mainstay of the initial treatment of multiple injured patients with hemorrhagic shock $[1,2]$. Trauma centers are requested to ensure timely and sufficient blood supply, without significant delays. In many hospitals, distance between blood bank and emergency room (ER) precludes an initial, direct supply of ER patients from the main hospital stock [3]. Marburg University Hospital holds a sealed blood product container in a certified blood fridge in the ER in which, according to the established local protocol, 6 units of group O, $\mathrm{RhD}+\mathrm{RBCs}, 2,000 \mathrm{IU}$ prothrombin complex concentrate and $2 \mathrm{~g}$ of fibrinogen are available for initiating the massive transfusion protocol (MTP). A clinical scoring system (Emergency Transfusion Score) is used to identify multiple injured patients who require MTP. Patient blood samples are taken before initiating the emergency transfusion, and regular blood group serology is performed on these samples. The decision to provide $\mathrm{RhD}+$ (instead of RhD-) RBCs in the ER was initially based on the fact that $85 \%$ of all patients are expected to be $\mathrm{RhD}+$; and $66 \%$ are expected to be male $[4,5]$, indicating that the majority of multiple injured patients is at low risk for $\mathrm{RhD}$ immunization and/or long-term effects associated with such an immunization (e.g., pregnancy). In addition, based on historical data, it was calculated that less than $50 \%$ of ER patients require immediate transfusions and that the additional safety which comes with a RhD- strategy would result in approximately 50 unnecessary $\mathrm{RhD}$ - transfusions (to $\mathrm{RhD}+$ recipients) per year.

This approach is supported by data from the US demonstrating that blood supply with non-cross-matched units of RBCs is safe in trauma patients [6-12]. Transfusion with $\mathrm{RhD}+\mathrm{RBCs}$ does not increase the rate of hemolytic transfusion reactions disproportionally

\section{KARGER}

(C) 2018 S. Karger GmbH, Freiburg

Fax +497614520714 
Table 1. Demographics of patients dependent on transfusion need after admission

\begin{tabular}{|c|c|c|c|c|c|}
\hline & Total & $\begin{array}{l}\text { Transfusion in ER } \\
\text { (first D+ RBCU via box) }\end{array}$ & $\begin{array}{l}\text { Transfusion in } 48 \mathrm{~h} \\
\text { (first TX not in ER) }\end{array}$ & No transfusion & $\mathrm{p}^{\#}$ \\
\hline Number of patients with PT, n (\%) & 823 & $62(7.5)$ & 78 & $485^{*}$ & \\
\hline Age in years, AM (SD) & 41.5 & $50.1(37.4)$ & $48.4(23.6)$ & $40.7(21.1)$ & 0.001 \\
\hline Male, \% & 73.3 & 69.6 & 72.6 & 75.8 & \\
\hline ISS, AM (SD) & 13.2 & $30.2(13.7)$ & $23.1(11.4)$ & $11.7(9.2)$ & 0.0001 \\
\hline Death, \% & 7.4 & 32.1 & 17.8 & 4.5 & \\
\hline Length of hospital stay in days, AM (SD) & 10.6 & $29.5(17.3)$ & $19.8(11.3)$ & $9.7(9.5)$ & 0.0001 \\
\hline Patients with clotting factors, $\mathrm{n}$ & 49 & 27 & 21 & 10 & \\
\hline Patients with further transfusions in $48 \mathrm{~h}, \mathrm{n}$ & - & 55 (798 RBCU) & n.a. & n.a. & \\
\hline Total number of RBCU (range) & 1,330 & $259(1-6)$ & $536(1-32)$ & n.a. & \\
\hline \multicolumn{6}{|c|}{ 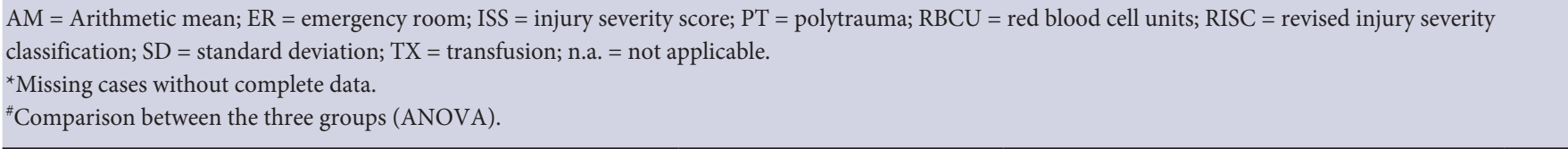 } \\
\hline
\end{tabular}

[12]. Mortality and morbidity were unchanged in trauma patients after $\mathrm{RhD}+$ transfusions $[13,14]$. These data were recently confirmed by results obtained in a German study [15].

In addition, several studies could demonstrate that the risk of $\mathrm{RhD}$ alloimmunization is relatively low in real life, ranging from 6 to $30 \%$ [15-18], compared to the $80 \%$ seroconversion rate calculated from early studies with healthy volunteers $[19,20]$.

Since data from Germany are sparse, we retrospectively analyzed data from the Marburg Polytrauma Database (DGU Trauma Register) and related information from the local safety update registry and the laboratory information system for a 5-year period.

\section{Material and Methods}

\section{Study Population}

We collected data from all multiple injured patients who received their first treatment in the ER between January 1, 2010 and December 31, 2014. Patients were identified in the Marburg Polytrauma Database. Transfusion history and serological results were traced back from the laboratory information system (Swisslab/Roche, Berlin, Germany). Information on additional side effects were collected from the safety update registry installed under European directive 2010/84/EU.

\section{Data Collection}

We collected age, sex, ISS (injury severity score), length of hospital stay, death, RISC II (revised injury severity classification), transfusion history, blood group in transfused patients, antibody screen, and side effects. In case of RhDincompatible transfusion, subsequent data for serology, hemolysis, and side effects were collected.

\section{Serological Investigation}

Blood group typing and antibody search were performed via solid-phase (SP) automated technology on Galileo instruments (Immucor, Rödermark, Germany). Serological follow-up of patients with RhD-incompatible transfusions included antibody screen via SP and column agglutination (CA; indirect antiglobulin test and enzyme test; BioRad, Dreieich, Germany). In case of suspected hemolytic transfusion reaction, a direct antiglobulin test (DAT) was performed by CA (BioRad). All DAT IgG-positives were further analyzed after acid elution.
Statistical Analysis

Descriptive statistics were performed using MS Excel 2010 (Microsoft Corp, Redmond, WA, USA). Descriptive data are given as mean and range or standard deviation (SD). Comparison between the groups was performed by ANOVA; $\mathrm{p}<0.05$ was considered to indicate significance.

\section{Results}

\section{Patient Cohort and Transfusion Events}

During the 5-year period, 823 multiple injured patients were treated in the ER. Their mean age was 42 years (range 2-89 years), $73 \%$ were male, the mean ISS was 13.2 , and the mean RISC II was 9.1\%. Mean trauma scores indicate that severity of injury in our trauma center showed average values when compared with data from Germany. Mean length of hospital stay was 10.6 ( \pm 12$)$ days, and 61 trauma patients (7.4\%) died in hospital.

The majority of patients in ER remained untransfused within the first $48 \mathrm{~h}(\mathrm{n}=683 ; 83 \%)$, whereas 62 patients $(7.5 \%)$ received $\mathrm{RBC}$ units from the sealed blood product container in ER immediately and $78(9.5 \%)$ were transfused within $48 \mathrm{~h}$, but not immediately in the ER. The demographics of all three groups are summarized in table 1 . Most of the patients $(n=55 ; 89 \%)$ with immediate transfusions in the ER required additional transfusion support during the next $48 \mathrm{~h}$ (on average 14.5 units; range 1-80 units). Nearly half of them were also infused with coagulation factors ( $\mathrm{n}=$ 27; 44\%). Further details for the 62 patients with immediate transfusions are summarized in table 2.

\section{Pre-Transfusion Antibody Status}

Antibody screen performed on the initial blood sample taken in ER was negative in 138/140 patients who received transfusions within $48 \mathrm{~h}$. One male patient of blood group $\mathrm{A} \mathrm{RhD}+$ had a warmreactive antibody of unknown specificity; and a female patient of blood group $\mathrm{O} \mathrm{RhD}$ - was diagnosed with anti-D. Both antibodypositive patients did not require immediate transfusions in ER and received compatible $\mathrm{RBC}$ units in the due course. 
Table 2. Characteristics of $\mathrm{RhD}$ - patients supplied with $\mathrm{RhD}+\mathrm{RBCU}$ and their immunohematological follow-up

\begin{tabular}{ll}
\hline & $2010-2014$ \\
\hline Total number of patients with PT & 823 \\
Total patients with TX & 140 \\
Total RBCU to all patients with TX & 1,330 \\
total patients with RBCU out of box & 62 \\
Total RBCU to patients with TX out of box & 259 \\
Total D- patients (of patients with TX) & $33^{*}(21 \%)$ \\
Number of D+ RBCU to D- patients (AM; range) & $245(13 ; 1-31)$ \\
Number of D+ RBCU to D- patients through box & 60 \\
Number of D- RBCU to D- patients (AM; range) & $82(7 ; 2-11)$ \\
Number of D- patients receiving D+ RBCU & 18 \\
Through box in ER & $14(22 \%)$ \\
Later on & 4 \\
Patients with additionally substitution & 10 \\
Anti-D in follow-up & 9 \\
Nonresponder (ABS negative after 1 year) & 3 \\
Death in hospital or during follow-up & 3 \\
No follow-up (no ABS after 120 days) & 3 \\
Hemolytic transfusion reaction & 0 \\
D- female in childbearing age with D+ RBCU & 3 \\
Patients with positive ABS before TX (1× no specificity, & 2 \\
1× anti-D) & \\
\hline & \\
\hline N & \\
\hline
\end{tabular}

$\mathrm{ABS}=$ Antibody screening; $\mathrm{AM}=$ arithmetic mean; $\mathrm{PT}=$ polytrauma; $\mathrm{RBCU}=$ red blood cell units; $\mathrm{TX}=$ transfusion.

*Two with unknown blood group, one of them with incomplete transfusion data.

\section{Transfusions in RhD- Multiple Injured Patients}

In total, $31 / 140$ patients $(21.5 \%)$ with transfusions within the first $48 \mathrm{~h}$ were typed $\mathrm{RhD}-.13$ patients received $\mathrm{RhD}-$ units throughout. 18 patients received $\mathrm{RhD}+$ units: 14 were directly transfused from the sealed blood product container in the ER, and 4 were switched from an initial $\mathrm{RhD}$ - transfusion to $\mathrm{RhD}+$ transfusions, after MTP was initiated. The mean number of all RBC units (including type $\mathrm{RhD}+$ and $\mathrm{RhD}-$ ) in incompatible transfused patients was 14,5 (range 1-37), and the mean number of RBC units in compatible transfused patients was 6.8 (range 2-11). Table 2 summarizes data from the $\mathrm{RhD}$ - patients only and the total number of transfused $\mathrm{RhD}+$ and $\mathrm{RhD}-\mathrm{RBCU}$.

\section{Seroconversion after RhD-Incompatible Transfusions}

Out of 18 patients with RhD-incompatible transfusions, 9 developed anti-D (50\%), three of whom also formed other antibody entities (anti-C, anti-E, and anti-K). The first follow-up investigation after the transfusion event was between day 3 and day 39, all without evidence for the presence of antibodies. The earliest seroconversion was detected at day 66; all other antibodies were detected at least 6 months after the incompatible transfusion event. No antibody formation was observed in 3 patients (follow-up period $>140$ days), indicating non-responder status. Three patients died in hospital (between day 1 and day 37), and 3 patients were lost on follow-up on day 5, 41, and 73 after the first incompatible transfusion, all with no signs of seroconversion up to then. No signs of hemolysis were evident in any of the patients (table 2).

\section{Patients of Childbearing Age}

Three out of the 18 patients were female and of childbearing age ( $<40$ years), with one of them being pregnant in week 31 of gestation. One patient received 2 units of incompatible RBCs, with no antibody formation (day 153). The other 2 patients went on MTP and both developed anti-D later. Fetal loss occurred within $48 \mathrm{~h}$ after the accident.

\section{Discussion}

In many tertiary care hospitals, the demand for blood group $\mathrm{O}$, $\mathrm{RhD}$ - units is larger than the supply made available by blood establishments. These units are specifically required for intrauterine transfusions, the transfusion of newborns, and patients with preformed antibodies [21]. Because of their almost universal compatibility, blood group $\mathrm{O}, \mathrm{RhD}$ - units are also often used in emergency transfusions in which the patient's blood group is unknown. RhDtransfusions are usually a precautionary measure in order to avoid anti-D immunization. In fact, this will turn out as unnecessary in most cases. It has been pointed out previously that the shortage of blood group $\mathrm{O}, \mathrm{RhD}-\mathrm{RBC}$ units even worsened, despite the overall decrease in $\mathrm{RBC}$ usage and the implementation of patient blood management strategies in many hospitals [21].

In this study, 62 multiple injured patients with a need for immediate transfusion received $259 \mathrm{RBC}$ units via the sealed box in $\mathrm{ER}, 199$ of which were given to $\mathrm{RhD}+$ patients. Accordingly, the overall number of saved $\mathrm{RhD}$ - units was 259 , and the overall number of correctly saved RhD- units was 199 (77\%). Vice versa, an $\mathrm{RhD}$ - transfusion strategy would have led to a waste of 199 RBS units over 5 years (40/year). These data match the study results of Newman et al. [22], who calculated a $72 \%$ rate of unnecessary $\mathrm{RhD}-\mathrm{RBC}$ transfusions. The demand for blood group $\mathrm{O}, \mathrm{RhD}-$ units in our hospital is between 800 and 900 per year, $6 \%$ of which can be saved with this strategy. If we include the RhD+ RBCU, given to the $\mathrm{RhD}$ - patients in the later course $(\mathrm{n}=185)$ but not via the sealed box in ER, the number of saved RBCU per year even raises to $77 /$ year $(8,5 \%)$. This rate may appear low, but is significant with respect to the shortage in blood group $\mathrm{O}, \mathrm{RhD}$ - supply.

The exposure rate $(\mathrm{RhD}$ - patients transfused with $\mathrm{RhD}+\mathrm{RBC}$ units) was $54 \%$ in our study, which was comparable to the $46 \%$ reported by Meyer et al. [14], and somewhat higher than the $20 \%$ reported by Selleng et al. [15]. Other studies [3, 8, 9, 11] reported well lower exposure rates $(6-7 \%)$, partially, because a limited number of $\mathrm{RhD}$ - units was also available in the $\mathrm{ER}[3,8,9]$. The British Guidelines recommend to use no more than 2 units of RBCs for patients with unknown blood group [23] and to switch to $\mathrm{RhD}+$ units in men, women of not childbearing age, and in MTPs, a recommendation that was implemented in many trauma centers [24]. In our cohort, however, only 2 patients required no more than 2 units of RBCs. Accordingly, the calculated exposure rate would only be marginally lower following this strategy (from 54\% to $48 \%$ ), but the unnecessary use of $\mathrm{RhD}$ - units would remain high (143 units). The German Guidelines are less specific when stating 
that $\mathrm{RhD}$-incompatible transfusions are sometimes unavoidable but should, whenever possible, be restricted to MTP and not be given to women of childbearing age at all [25].

The seroconversion rate in $\mathrm{RhD}$ - recipients of $\mathrm{RhD}+\mathrm{RBCs}$ was $50 \%$ in this study. We included all patients who died in the clinical course or who were lost to follow-up, because we believe that this represents the effective, observed conversion rate. It should be noted that this rate is comparable to the $45 \%$ reported by Selleng et al. [15], who did not include patients lost by death, but did include 'potential' seroconverters. We believe that our relatively long follow-up period affects the seroconversion rate significantly. Most other studies reported seroconversion rates between 9.5 and 33\% with mean follow-up periods of $14-74$ days $[9,11,12,14]$. Since most multiple injured patients are not immunosuppressed per se, anti-D formation is to be expected more often than in patients with bone marrow transplants or sepsis [26-29].

In our study, immunization against RhD did not depend on the number of transfused units. Findings from others point in the same direction [15-17]. Interestingly, a strategy according to the British Guidelines would not have affected the number of seroconverters.

Apparently, transfusing $\mathrm{RhD}+$ blood exposes patients with preformed anti-D to higher risk. Unfortunately, literature on incompat- ible emergency transfusions is sparse. The authors identified one case where the incompatible transfusion in an emergency setting was due to a preformed anti-c antibody [12]. This example demonstrates that $\mathrm{RhD}$ - transfusions are not 'universally' compatible. A second case describes boostering of preformed, undetectable anti-Jk(a) antibodies [11]. No general conclusion can be drawn from these data.

Given the fact that restricted supply with blood group $\mathrm{O}, \mathrm{RhD}-$ units is unlikely to change in near future, we believe that supplying multiple injured, exsanguinated patients with blood group $\mathrm{O}$, $\mathrm{RhD}+$ units is an acceptable strategy. Whether this procedure leads to reduced numbers of $\mathrm{RhD}$-incompatible transfusions for patients in elective or semi-urgent settings is currently being evaluated.

\section{Acknowledgment}

The authors would like to thank Mrs. Renate Marschall for excellent support in data acquisition.

\section{Disclosure Statement}

The authors have no potential conflicts of interest to declare.

\section{References}

1 Deutsche Gesellschaft für Unfallchirurgie (federführend): S3 - Leitlinie Polytrauma/ SchwerverletztenBehandlung. www.awmf.org/leitlinien/detail/ll/012019.html (last accessed February 20, 2018)

2 British Committee for Standards in Haematology, Stainsby D, MacLennan S, Thomas D, Isaac J, Hamil ton PJ: BCSH Guidelines on the management of massive blood loss Br J Haematol 2006;135:634-641.

3 Murthi SB, Dutton RP, Edelman BB, Scalea TM, Hess JR: Transfusion medicine in trauma patients. Expert Rev Hematol 2008;1:99-109.

4 Reid M, Lomas-Francis C, Olsson ML: The Blood Group Antigen Facts Book, 3rd ed. New York, Elsevier, 2012.

5 Lefering R, Huber-Wagner S, Nienaber U. Maegele M, Bouillon B: Update of the trauma risk adjustment model of the TraumaRegister DGUTM: the revised injury severity classification, version II. Crit Care 2014;18:476.

6 Gervin AS, Fischer RP: Resuscitation of trauma patients with type-specific uncrossmatched blood. J Trauma 1984;24:327-331.

7 Schwab CW, Shanye JP, Turner J: Immediate trauma resuscitation with type $\mathrm{O}$ uncrossmatched blood: a twoyear prospective experience. J Trauma 1986;26:897-902.

$\checkmark 8$ Lefebre J, McLellan BA, Coovadia AS: Seven years' experience with group $\mathrm{O}$ unmatched packed red blood cells in a regional trauma unit. Ann Emerg Med 1987; 16:1344-1349.

9 Dutton RP, Shih D, Edelman B, Hess J, Scalea TM: Safety of uncrossmatched type-O red cells for resuscitation from hemorrhagic shock. J Trauma 2005;59:1445-1449.

10 Inaba K, Teixeira PGR, Shulman I, Nelson J, Lee J, Salim A, Brown C, Demetriades D, Rhee P: The impact of uncrossmatched blood transfusion on the need for massive transfusion and mortality: analysis of 5,166 uncross-matched units. J Trauma 2008;65:1222-1226.

11 Miraflor E, Yeung L, Strumwasser A, Liu T, Victorino GP: Emergency uncrossmatched transfusion effect on blood type alloantibodies. J Trauma 2011;72:48-53.
Mulay SB, Jaben EA, Johnson P, Badjie K, Stubbs J: Risks and adverse outcome associated with emergency-release red blood cell transfusion. Transfusion 2013;53:1416-1420.

13 Schmidt PJ, Leparc GF, Samia CT: Use of Rh positive blood in emergency situations. Surg Gynecol Obstet 1988; 167:229-233.

14 Meyer E, Uhl L: A case for stocking O D+ red blood cells in emergency room trauma bay. Transfusion 2015;55:791-795.

15 Selleng K, Jenichen G, Denker K, Selleng S, Müllejans B, Greinacher A: Emergency transfusion of patients with unknown blood type with blood group O Rhesus $\mathrm{D}$ positive red blood cell concentrates: a prospective single-centre, observational study. Lancet Haematol 2017;4:e218-e224.

16 Frohn C, Dümbgen L, Brand J-M, Görg S, Luhm J, Kirchner H: Probability of anti-D development in D-patients receiving D+ RBCs. Transfusion 2003;43:893-898.

17 Yazer MH, Triulzi DJ: Detection of anti-D in D-recipients transfused with D+ red blood cells. Transfusion 2007;47:2197-2201.

18 Gonzalez-Porras JG, Graciani IF, Perez-Simon JA, Martin-Sanchez J, Encinas C, Conde MP, Nieto MJ, Corral M: Prospective evaluation of a transfusion policy of D+ red blood cells into D- patients. Transfusion 2008;17:1318-1324.

19 Gunson HH, Stratton F, Cooper DG, Rawlinson VI: Primary immunization of Rh-negative volunteers. $\mathrm{Br}$ Med J 1970;1:593-595.

20 Urbaniak SJ, Robertson AE: A successful program of immunizing Rh-negative male volunteers for anti-D production using frozen/thawed blood. Transfusion 1981;21:64-69.

21 Beckman N, Yazer M, Land K, Chesneau S, Cauldfield J: Blood banks meet the paradox of Gabriel's Horn: what are the options to maintain supply as demand decreases? Transfus Med 2016;26:170-176.
22 Newman BH, Shafer AW, Saeed SM: Patterns of use of group $\mathrm{O}$, Rh-negative red cells in a large metropolitan area and an action plan to control utilization. Transfusion 1996;36:209-212.

23 NHS, The Chief Medical Officer's National Blood Transfusion Committee: The appropriate use of group O RhD negative red cells. www.transfusionguidelines.org/document-library/documents/nbtc-recommendations-on-theappropriate-use-of-group-0-rhd-negative-red-cells-revised-april-2009/download-file/nbtc_bbt_o_neg_red_

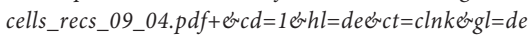
(last accessed February 22, 2018).

24 Schäfer N, Driessen A, Fröhlich M, Stürmer EK, Maegele M; TACTIC partners:. Diversity in clinical management and protocols for the treatment of major bleeding trauma patients across European level I Trauma Centres. Scand J Trauma Resusc Emerg Med 2015;23:74.

25 German Guidelines for Production of Blood and Blood Derived Factors and for Hemotherapy. Cologne, Deutscher Ärzteverlag, 2017, chapter 4.10.5.

26 Ramsey G, Hahn LF, Cornell FW, Boczkowski DJ, Staschak S, Clark R, Hardesty RL, Griffith BP, Starzl TW: Low rate of rhesus immunization from Rh-incompatible blood transfusions during liver an heart transplant surgery. Transplantation 1989;47:993-995.

27 Schonewille H, Haak HL, Zijl AM: Alloimmunization after blood transfusion in patients with hematologic and oncologic diseases. Transfusion 1999;39:763-771.

28 Asfour M, Narvios A, Lichtiger B: Transfusion of RhDincompatible blood components in RhD-negative blood marrow transplant recipients. Med Gen Med 2004;13:22.

29 Casanueva M, Valdes MD, Ribera MC: Lack of alloimmunization to D antigen in D-negative immunosuppressed liver transplant recipients. Transfusion 2008; 34:570-572. 